\title{
Measuring Appreciative Inquiry, Lean and Perceived Co-worker Health
}

DOI: 10.12776/QIP.V20I2.744

\author{
Ingela Bäckström, Pernilla Ingelsson \\ Received 27 June 2016, Revised 28 July 2016, Accepted 19 September 2016
}

\begin{abstract}
Purpose: The purpose of this paper is to present a developed questionnaire which measure Appreciative Inquiry, Lean values and co-workers health. The purpose is also to explore if and how Appreciative Inquiry correlates with Lean values and co-workers' perceived health in an organisation working with Lean.
\end{abstract}

Methodology/Approach: To investigate the relationship between Lean, Appreciative Inquiry and perceived co-worker health, a questionnaire was developed based on two previously tested questionnaires. The new questionnaire was answered by 841 co-workers at a Swedish municipality and was then analysed to explore in what way Appreciative Inquiry correlates with a number of Lean values as well as perceived co-worker health.

Findings: All variables were found to be significantly correlated with the variable 'Appreciative Inquiry'. The variable 'Continuous improvements' relates most to 'Appreciative Inquiry' followed by 'Eliminating Waste' as those variables can be considered to have a large positive relationship. 'Supportive Leadership' and 'System view' have a medium positive relation to 'Appreciative Inquiry' and the variables 'Health' and 'Customer focus' have a small relation to Appreciative Inquiry in this context.

Category: Case study

Keywords: Supportive leadership, Lean values, co-worker health, Appreciative Inquiry 


\section{INTRODUCTION}

Global competition is constantly increasing, and this, together with the low-wage economies of the developing world, poses a substantial challenge to managers in the manufacturing, service and public service sectors (Radnor and Barnes, 2007). To meet this demand and to endorse changes and progress toward business excellence, management initiatives such as Quality Management (QM), Lean, Business Process Reengineering and Integral Health Management have been used, see for instance (Zwetsloot and Pot, 2004; Docherty, 2002). Those approaches are frequently deficit-based which means that they focus on problems and how to overcome them. When focusing on problems instead of possibilities, organisations are prevented from using their full potential which leads to decreased organisational capacity (Whitney and Trosten-Bloom, 2010). New managers request support to change the culture and need plans and approaches to reinforce positive loops in their workplaces (Calabrese, Cohen and Miller, 2013). By using Appreciative Leadership, the creative potential among co-workers can be organised and shaped into positive power (Whitney and Trosten-Bloom, 2010). This is important as work-life balance has a major influence not only on business productivity but also on the economy as a whole (Hughes, 2007). Wolf (2008) states that there are massive consequences for the workplace as mental sickness goes hand in hand with significant productivity losses. Many reasons for sickness absence are work-related and organisational but also affected by other factors (Janssen, et al., 2003). This paper focuses on the QM initiative Lean. Lean can have both positive and negative effects on the working environment and it depends on how it is practiced within the organisation (Hasle, et al., 2012). Recent research has found positive correlations between Lean values, Lean Leadership and co-workers' perception of their health (Bäckström and Ingelsson, 2015) but Lean has also been criticized for impacting negatively on the working environment. Research of the use of Appreciative Inquiry has increased drastically in recent years especially in public organisations (see for instance Carter, 2006), but research combining Lean and Appreciative Inquiry is rather rare (Hansen, 2015).

The purpose of this paper is to present a developed questionnaire which measure Appreciative Inquiry, Lean values and co-workers health. The purpose is also to explore if and how Appreciative Inquiry correlates with Lean values and coworkers' perceived health in an organisation working with Lean.

\subsection{Appreciative Inquiry}

Appreciative Inquiry is an initiative which borrows practices from the context of organisational development and is an incentive for a positive revolution in change (Whitney, Trosten-Bloom and Rader, 2010). According to Watkins and Cooperrider (2000), it is a theory, an approach and a mind-set used for analysing which leads to creativity and organisational learning. The Appreciate Inquiry activities, practices and processes focus on what is best for the organisation - in 
the past, present and the future (Whitney, Trosten-Bloom and Rader, 2010). Bushe (2007), stresses the importance of generativity within Appreciative Inquiry, which he considers is both an input and an outcome. Cooperrider and Srivastva (1987), also argue that generativity is the core of Appreciative Inquiry. According to Grant and Humphries (2006), Appreciative Inquiry is rooted in the primes that language, knowledge, and action are inextricably linked, i.e. the ontological positions of social constructionists. Hence the language and behaviour are in focus in Appreciative Inquiry instead of social structure (Dematteo and Reeves, 2011).

In contrast to a deficit-based approach, Appreciate Inquiry is a positive approach to change, (Whitney, Trosten-Bloom and Rader, 2010), where generativity is in focus instead of problem-solving (Bushe, 2007). The problems should not be ignored, however by focusing on strengths, this approach is more effective, mainly when a change of situation, relationship, organisation or a community is wanted (Whitney, Trosten-Bloom and Rader, 2010). Appreciative Inquiry supports leaders in generating natural human organisations - knowledge-rich, strength-based, adjustable learning organisations (Whitney and Trosten-Bloom, 2010). According to Cooperrider's and Srivastava's research (1987), the focus on expanding successful experiences rather than problem detection leads to more creative and faster cultural change. The Appreciative Inquiry approach has played a central part in inspiring, engaging and empowering co-workers (Dematteo and Reeves, 2011). The Appreciative Inquiry approach also gives managers huge potential to create a culture of trust and collaboration based on respect (ibid).

\subsection{Lean values}

Lean is a management system considered to be receptive to the needs of people in business and bring better outcomes for key stakeholders (Emiliani, et al. 2003). Different values and principles have been defined by different researchers as the fundamental ingredients of Lean (see e.g. Liker, 2004; Womack \& Jones, 2003 and Emiliani, 2010). Womack \& Jones (2003) defined five principles of Lean and Liker (2004) describes Lean through 14 principles divided into four parts of a pyramid. Emiliani (2010) claims that the two main principles 'continuous improvement' and 'respect for people' need to permeate the organisation in order to achieve "real Lean" in oppose to "fake Lean" that is an overemphasis on continuous improvement. He further states that 'Your greatest challenge in Lean management will be to practice and deepen your understanding of the "respect for people" principle' (ibid p 53). The principle "respect for people" is usually ignored by senior management and this is something that needs to be corrected (Emiliani and Emiliani, 2013).

When an organisation applies Lean, the starting point should be to continuously benefit the customer and not for internal company reasons (Emiliani, 2010). According to Bicheno \& Holweg (2009), the most common theme within Lean is 
the external customer. The customer defines the values which are the critical starting point for Lean (Womack \& Jones, 2003). Along with customer focus, the values continuous improvement, supportive leadership, system view and eliminate waste are also very apparent within Lean (see, for instance, Liker, 2004 and Emiliani, 2007). Liker and Franz (2011) state that continuous improvement within Lean is more than problem solving; it is a way to think and how the organisation learns. The value is also the last principle defined by Womack and Jones (2003) as well as the top of Liker's (2004) 4P pyramid suggesting that continuous improvement is the ultimate step in a Lean implementation. Bicheno \& Holweg (2009), define a system approach as focusing on the organisation as a whole before paying attention to the parts. Womack \& Jones (2003) claim that Lean stresses the supply chain seen as a value stream from the sub-suppliers to the ultimate customer. According to Seddon (2005), managing the organisation as a system consists among other things of having a design based on customer demand, value and flow. The elimination of waste is closely linked to creating flow in an organisation's processes (Liker, 2004 and Womack \& Jones, 2003). The seven traditional wastes were defined by Taichii Ohno as: overproduction, waiting, unnecessary motions, transporting, over-processing, unnecessary inventory and defects (Bicheno \& Holweg, 2009). Often untapped human potential is added as an eighth type of waste.

When working with Lean, the organisational culture is of importance. Liker (2004) argues that a mistake that is often made is to view Lean as a number of tools when in fact the tools are parts of a whole. They are not enough if you want to change an organisation's activities; in that case you need a deeper cultural change (ibid). Al-Najem, Dhakal and Bennett (2012) state that in order to succeed with Lean you need a healthy culture, skilled co-workers and a top management that understand and have bought the concept. In the work with achieving this organisational culture, leaders and leadership are crucial; there is a need for supportive leadership with focus on continuous improvements. According to Liker (2004), the manager's role is to change the culture through involving themselves in the actual work of identifying waste and value stream mapping. Liker (2004), further states that the managers within Lean are passionate about involving people and they have an in-depth understanding of the work as well as general managerial knowledge. Dombrowski \& Mielke (2013) argue that the Lean leader can promote a better improvement culture through being a role model for his or her co-workers. Emiliani (2003) suggests that Lean leadership capabilities are built up via direct observation and participation in continuous improvement activities. According to Spear (2004), the values of Lean can be reflected in four lessons where the fourth is "managers should coach not fix".

\subsection{Appreciative Inquiry and Lean}

Hansen (2015) states that Appreciative Inquiry can be a way of adding new methods supporting any improvement strategy helping to address both realisation 
efficiency and competence building. This is done not only in order to eliminate problems and short-term results but to also build an organisation's improvement capabilities. Combining Appreciative Inquiry and Lean could lead to new ways of addressing organisational challenges. Kongsbak (2010) describes the results from an organisation that combined Appreciative Inquiry and Lean in order to come to terms with high absenteeism and low productivity. The company had worked with Lean for a couple of years and by introducing the Appreciative Inquiry approach and letting the whole company dream of being 'most wanted as a facility and employees'. Over a period of two years they reached results within a number of areas. For example, the cycle time was reduced by $80 \%$, customer complaints decreased by $10 \%$ and the employee satisfaction survey increased from 3.6 to 4.37 on a scale from 1 to 5 (ibid).

Hansen (2012) states that the challenge in combining the two concepts is their different assumptions and basic approaches. He exemplifies some of the differences in relation to the approaches to create different improvements in an organisation (see Table 1).

Table 1 - Typical approaches in Appreciative Inquiry and Lean (Hansen, 2012)

\begin{tabular}{|l|l|l|}
\hline Approach to create... & Lean & Appreciative Inquiry \\
\hline value for the customer & Eliminate waste & Look for and grow value \\
\hline efficiency and flow & Remove bottlenecks & $\begin{array}{l}\text { Identify and expand best } \\
\text { practice }\end{array}$ \\
\hline effectiveness and quality & Reduce defects & $\begin{array}{l}\text { Study and learn from } \\
\text { perfection for the customer }\end{array}$ \\
\hline continuous improvements & $\begin{array}{l}\text { Identify problems, analyse } \\
\text { root causes and fix them }\end{array}$ & $\begin{array}{l}\text { Identify best practice, explore } \\
\text { success factors and dream and } \\
\text { design to improve }\end{array}$ \\
\hline
\end{tabular}

\subsection{Perceived co-worker health}

Resent research shows that QM practices are related to co-workers' well-being in a positive way (Liu and Liu, 2014), in the sense that QM can help co-workers to increase their feelings of belongingness and satisfaction but also reduce their work stress and work overload (ibid). According to Arnetz (2002), leaders have the opportunity to affect how co-workers view and experience efficiencies within their organisations. He proposes that co-workers who work in efficient organisations tend to be happier. This positive approach towards work offers an inclusive measure that shows both the level of balance between co-workers and organisations (ibid). Leadership inspired by Appreciative Inquiry has shown to affect the working environment in a positive way and decrease sick leave (Åslund, Bäckström and Richardsson, 2011). Something that is reinforced by Kongsbak (2010) who reports a decrease in absenteeism of 50\% (from $12 \%$ to $6 \%$ ) as one of the results from their work in combining Lean and Appreciative Inquiry. 
A shared way of measuring co-worker health is by asking them about their health through questionnaires or interviews (Westlund and Löthgren, 2001). Theorell and Vogel (2003) argue that self-reported health is a respected indicator of coworker health. On the other hand, there are complications in comparing selfreported health. Complications arise when the statements in the questionnaires are to be verbalized and additionally, the same word can have a different meaning to different co-workers (Nyberg, et al., 2005). Regardless of the difficulties in comparing and measuring co-worker health, self-reported health is one way to measure it and provides valuable information for further research (ibid).

\section{METHODOLOGY AND CASE DESCRIPTION}

To investigate the relationship between Lean, Appreciative Inquiry and perceived co-worker health, a questionnaire was developed based on two previously tested questionnaires. They both consist of a number of statements aiming at measuring different variables. One that measures co-workers' perceived health has been developed and tested by Lagrosen, Bäckström and Wiklund (2012) and has been used and re-developed in various research projects (see for instance Bäckström, Eriksson and Lagrosen, 2012a; Bäckström, Wiklund and Ingelsson, 2012b and Bäckström, Eriksson and Lagrosen, 2014). The other questionnaire measures a number of Lean values and has also been developed, tested and re-developed when used in different research projects, see Ingelsson, Bäckström and Wiklund (2010), Ingelsson (2013) and Ingelsson and Mårtensson (2014).

With those two questionnaires as a base, a new questionnaire with the purpose of measuring Lean values, Appreciative Inquiry and co-workers' perceived health was developed. The new questionnaire was compiled with three to five statements for the health index, Lean values and Appreciative Inquiry. The calculated variables consisting of three to five statements are formulated as follows:

Health:

1. I am usually alert.

2. I think my health is very good

3. I am almost always healthy

Continuous improvement:

1. We are constantly working on getting better in everything we do

2. We have time to work with improvements in everyday work

3. There is a standardized way of working with improvement in everyday work.

4. We focus on how we can improve things not on who made a mistake

System view:

1. I know what over-all goals the organisation has 
2. I know how the work I do is connected to other parts of the organisation

3. I know how my work contributes to the over-all goals of the organisation Customer focus:

1. I know who our customers are

2. I know what creates value for our customers

3. I know what our customers' needs are

Eliminate waste:

1. To eliminate waste is something we work with continuously

2. I know how to identify waste in my work

3. We solve problems when and where they arise

Supportive Leadership:

1. Our managers take responsibility for their actions

2. Our managers are constantly working to improve their own ways of working

3. Our managers are present in everyday work

4. There is a clear demand from our management that we should work with continuous improvements

5. Our managers are supporting us in our work with continuous improvements

The statement for the new variable, Appreciative Inquiry, was developed from theory (Hansen, 2012) and formulated as:

1. When things go really well, we usually take the time to understand the reason why

2. We often use our successes as a driver and the starting point for development

3. We often talk about our strengths and what we are really good at

A case study was carried out, using the questionnaire, in a small municipality in southern Sweden with about 15000 inhabitants. The municipality was chosen as they have worked with Lean for several years. It employs 1208 people and their human resources policy is based on the cornerstones of leadership, competence and participation. The municipality started to work with a common set of values in 1992 and since 2006 they have focused on Lean. They have not worked in a deliberate and structured way with Applicative Inquiry even though some of their values reflect the assumptions of the concept. Their fundamentals of Lean are:

- Supportive leadership

- Addressing the skills of employees

- Focus on value-adding activities

- Eliminate waste 
- Long-term, holistic thinking

- Continuous improvement, step by step

- Simple tools

- No scapegoating

The municipality had a sick leave rate of $6.3 \%$ in 2013 among its permanent coworkers, which was an increased rate compared with 2012. They had a goal to reduce the sick leave rate to $3 \%$ in 2015 . Unfortunately the sick leave rate increased to $7.2 \%$ in 2014 and the goal seems hard to achieve.

The study was carried out during the municipality's 40-hour residential course at Pärnu, Estonia, a course in which 1074 co-workers and leaders participated. There were seven occasions in the fall of 2013 when the different co-workers were gathered and the questionnaire was handed out and collected by the researchers. A total of 841 co-workers filled in the questionnaire, which gives a response rate of $70 \%$ of all co-workers and $78 \%$ of those who were present when the questionnaire was handed out. They were asked to mark on a seven-point agreement scale from 'Disagree strongly' to 'Agree strongly' to what extent they agreed with the statements. The data were then entered into the statistical program SPSS for further analysis.

The results from the questionnaire were first analysed to check the internal consistency and reliability between the variables for Health, Lean values and Appreciative Inquiry, by calculating the Cronbach Alpha. Secondly, the results were analysed in order to examine the relationship between Lean values and perceived co-worker health and the result was recently presented in Bäckström and Ingelsson (2015). The mean value and the standard deviation of each variable was also calculated. In order to meet the purpose of exploring if and how Appreciative Inquiry correlates with Lean values and co-workers' perceived health, the Pearson Correlation was calculated. In addition, the Spearman's coefficient of rank correlation was also calculated.

\section{RESULTS}

The results of the internal consistency reliability test of the variables are presented in Table 2. The test shows Cronbach Alpha values from 0.68 to 0.82 which can be considered as acceptable when three to five statements have been used. The mean value and the standard deviation for each variable are also presented in Table 2.

Customer focus has the highest mean value with 6.36 on the seven-point agreement scale and Appreciative Inquiry the lowest with 4.57. There is also some variation in the data where 'Appreciative Inquiry' and 'System view' have the highest standard deviation indicating a substantial variation in perception of those variables among the co-workers. 
Table 2 - Cronbach Alpha, mean and standard deviation for Appreciate Inquiry, Health, and Lean values.

\begin{tabular}{|l|c|l|l|l|}
\hline Variable & $\begin{array}{l}\text { No of } \\
\text { Statements }\end{array}$ & $\begin{array}{l}\text { Cronbach } \\
\text { Alpha }\end{array}$ & Mean & St dev \\
\hline Appreciative Inquiry & 3 & 0.71 & 4.57 & 1.10 \\
\hline Health & 3 & 0.78 & 5.78 & 1.00 \\
\hline Eliminating waste & 3 & 0.69 & 4.81 & 1.09 \\
\hline Continuous improvement & 4 & 0.70 & 5.05 & 0.98 \\
\hline Customer focus & 3 & 0.68 & 6.36 & 0.67 \\
\hline Supportive Leadership & 5 & 0.82 & 5.46 & 1.03 \\
\hline System view & 3 & 0.71 & 5.37 & 1.10 \\
\hline
\end{tabular}

The results of the calculated Pearson and Spearman correlation between the variables of Lean values and Health and its connection to the variable 'Appreciative Inquiry' are presented in Table 3. As can be seen in the table, all variables were positively highly and significantly correlated with the variable 'Appreciative Inquiry' but a low strength of correlation can be highly statistically significant with a large sample, such as in this case. The variable 'Continuous improvements' relates most to Appreciative Inquiry followed by 'Eliminating Waste' as those variables can be considered to have a large relation according to Cohen (1988). 'Supportive Leadership' and 'System view' have a medium positive relation to 'Appreciative Inquiry' and the variables 'Health' and 'Customer focus' have a small relation with Appreciative Inquiry in this context (ibid).

Table 3 - Correlations between Appreciate Inquiry and Health and Lean values.

\begin{tabular}{|l|l|l|l|l|}
\hline Variables & Pearson & Sig. & Spearman & Sig. \\
\hline Continuous improvements & $0.627^{* *}$ & 0.000 & $0.628^{* *}$ & 0.000 \\
\hline Eliminating Waste & $0.555^{* *}$ & 0.000 & $0.536^{* *}$ & 0.000 \\
\hline Supportive Leadership & $0.476^{* *}$ & 0.000 & $0.476^{* *}$ & 0.000 \\
\hline System view & $0.368^{* *}$ & 0.000 & $0.370^{* *}$ & 0.000 \\
\hline Health & $0.234^{* *}$ & 0.000 & $0.219^{* *}$ & 0.000 \\
\hline Customer focus & $0.262^{* *}$ & 0.000 & $0.267^{* *}$ & 0.000 \\
\hline
\end{tabular}

** Correlation is significant at the 0.01 level.

\section{CONCLUSION AND DISCUSSION}

The presented and tested questionnaire can be used to measure to what extent the values Appreciative Inquiry, Lean values and co-workers health permeates organisations since the internal consistency for all variables can be considered 
acceptable. It can be used as a tool for measuring the start of a Lean initiative as well as monitoring progress. The questionnaire can also be used in order to investigate to what degree those variables correlate in order to see what variables are connected and what areas to focus on.

The result from the municipally shows that all the mean values of the calculated variables have a proportionately high value. The lowest are Appreciative Inquiry, which is not strange as the organisation has not worked with that approach. The variable 'Health' which measures co-workers perception of their health had the second highest mean value with 5.78 on a seven-point scale. At the same time, the sick leave is high in the municipality but those co-workers on sick leave did not have the opportunity to fill in the questionnaire. The sick leave among the coworkers had also increased during the last two years although they had worked especially with those issues and with Lean. As earlier research has found connections with Appreciative Inquiry initiative and healthy co-workers (Kongsbak, 2010; Åslund, Bäckström and Richardsson, 2011), a good piece of advice to the organisation is to start working with the Appreciative Inquiry approach in combination with the Lean initiative they have already started. This is also in line with Al-Najem, Dhakal and Bennett (2012) who argues that in order to succeed with Lean, the organisation needs a healthy culture, skilled coworkers and a top management that understand and have bought the concept.

The correlation between Appreciative Inquiry and the co-workers' perception of their health was positive but there was a low correlation in this case. Appreciative Inquiry may help the organisation to work in a structured and conscious way to increase the sick leave. The co-workers present at work consider themselves to be healthy but a structured and conscious way of working with Appreciative Inquiry may prevent more co-workers from getting sick and encourage development. The Lean value 'Continuous improvements' has the strongest relation to Appreciative Inquiry. This could indicate that the organisation is working with Continuous improvements with a positive "touch" which in turn can indicate that they not only eliminate problems and achieve short-term results but also build the organisation's improvement capabilities (Hansen, 2012).

Customer focus has the highest mean value with 6.36 on the seven-point agreement scale in this case which can be considered as a result of their Lean improvement work but also an unusual result as the investigated organisation is a municipality. The results show that their Lean improvement is done according to Emiliani (2010), who claims that the work with Lean should be to benefit the customer and not for internal company reasons. It is also in line with Bicheno \& Holweg (2009), who argue that the most common subject within Lean is the external customer and Womack \& Jones (2003), who maintain that the customer defines the values which form the critical starting point for Lean. This is an additional indication that their Lean improvement work has been successful and that they are ready to take the next step and combine Lean with Appreciative Inquiry in a way similar to what Kongsbak (2010) describes, a case where they had decreased their absenteeism by $50 \%$. 


\section{FUTURE RESEARCH}

Can the correlation between Appreciative Inquiry and the co-workers' perception of their health have been influenced by the fact that the organisation has not worked with Appreciative Inquiry in a structured way? That is an interesting question that deserves to be investigated further in future research projects in the studied organisation.

The value 'respect for people' is highlighted by researchers as well as by Toyota themselves (Emiliani, 2012). It is also pointed out that the lack of focus on this value leads to 'fake Lean' when striving to eliminate problems and focus on short-term results is done at the expense of 'respect for people'. It would be interesting to further develop the questionnaire to include the value 'respect for people' and to examine closer the relationship between Appreciative Inquiry and 'respect for people'. Could it be that Appreciative Inquiry is the key to new structured way of accomplishing 'real Lean' since Calabrese, Cohen and Miller (2013) claim that the Appreciative Inquiry approach gives the managers huge potential to create a culture of trust and collaboration based on respect?

\section{REFERENCES}

Al-Najem, M., Dhakal H.N. and Bennett, N., 2012. The role of culture and leadership in lean transformation: a review and assessment model. International Journal of Lean Thinking, 3(1), pp.119-138.

Arnetz, B., 2002. Organisationsstress. Ledningsperspektiv på organisationer och hormoner i förändring. In Stress, molekylerna, individen, organisationen, samhället. Ekman, R. and Arnetz, B.B. (Eds.) Stockholm: Liber.

Åslund. A, Bäckström, I. and Richardsson, D., 2011. Managing Appreciative Leadership to Create efficiency organizations and healthy co-workers? In: Proceedings of ICQSS 2011, 14th OMOD Conference on Quality and Service Sciences, San Sebastian.

Bäckström, I. and Ingelsson, P., 2015. Is there a relationship between Lean Leaders and healthy co-workers? Quality Innovation Prosperity, 19(2), pp.123136.

Bäckström, I., Eriksson, L. and Lagrosen, Y., 2012a. A health-related quality management approach to evaluating health promotion activities, International Journal of Quality and Service Sciences, 4(1), pp.76-85.

Bäckström, I., Eriksson, L. and Lagrosen, Y., 2014. Change of the quality management culture through health-promotion activities? Total Quality Management and Business Excellence, 25(11-12), pp.1236-1246.

Bäckström, I., Wiklund, H. and Ingelsson, P., 2012b. Measuring the Starting Points for a Lean Journey. In: Proceedings of 15th QMOD conference on Quality and Service Sciences ICQSS 2012, September, 2012, Poznan, Poland. 
Bicheno, J. and Holweg, M., 2009. The Lean Toolbox: The essential guide to Lean transformation. Buckingham: PICSIE Books.

Bushe, G.R., 2007. Appreciative Inquiry Is Not (Just) About The Positive. OD Practitioner, 39(4), pp.30-35.

Calabrese, R., Cohen, E. and Miller, D., 2013. Crating a Healthy workplace Culture Using an Appreciative Inquiry 4-D Cycle. Organization Management Journal, 10(3), pp.196-207.

Carter, B., 2006. One expertise among many - working appreciatively to make miracles instead of finding problems. Journal of Research in Nursing, 11(1), pp.48-63.

Cohen, J.W., 1988. Statistical Power Analysis for the Behavioural Sciences. New Jersey: Lawrence Erlbaum Associates Hillsdale.

Cooperrider, D.L. and Srivastva, S., 1987. Appreciative inquiry in organizational life. In W.A. Pasmore and R.W. Woodman (eds.), Research in Organizational Change and Development. 1, pp.129-169. Greenwich, CT: JAI Press.

Dematteo, D. and Reeves, S., 2011. A critical examination of the role of appreciative inquiry within an interprofessional education initiative. Journal of Interprofessional Care, 25(3), pp.203-208.

Docherty, P., 2002. Creating Sustainable Work Systems - Emerging perspectives and practice. London: Taylor \& Francis Ltd.

Dombrowski, U. and Mielke, T., 2013. Lean Leadership - Fundamental Principles and their Application. Procedia CIRP, 7(0), pp.569-574.

Emiliani, B., 2007. Real Lean understanding the lean management system. Wethersfield, Conn.: The Center for Lean Business Management, LLC.

Emiliani, B., 2010. Moving forward faster: the mental evolution from fake Lean to REAL Lean. Wethersfield, Conn.: The Center for Lean Business Management, LLC.

Emiliani, B., Stec, D.J., Grasso, L. and Stodder, J., 2003. Better thinking, better results: Using the power of Lean as a total business solution. Kensington, Conn.: Center for Lean Business Management.

Emiliani, M. and Emiliani, M., 2013. Music as a framework to better understand Lean Leadership. Leadership \& Organization Development Journal, 34(5), pp.407-426.

Emiliani, M.L., 2003. Linking leaders' beliefs to their behaviors and competencies. Management Decision, 41(9), pp.891-910.

Grant, S. and Humphries, M., 2006. Critical evaluation of appreciative inquiry: Bringing an apparent paradox. Action Research, 4(4), pp.401-418. 
Hansen, D., 2012. Appreciative Problem Solving. Paper presented at the 2012 World Appreciative Inquiry Conference.

Hansen, D., 2014. Decoding the productivity code - Towards and improvement theory for sustainable organizational performance. Doctoral Thesis no 7.2014 at Department of Management Engineering, Kopenhagen, Technical University of Denmark - DTU.

Hansen, D., 2015. What's Your Next Move? Quality Progress, 48(6), pp.16-22.

Hasle, P., Bojesen, A., Jensen, P.L. and Bramming, P., 2012. Lean and the working environment: a review of the literature. International Journal of Operations \& Production Management, 32(7), pp.829-849.

Hughes, N., 2007. Is life a balancing act? Industrial and commercial training, 39(5), pp.281-284.

Ingelsson, P. and Mårtensson, A., 2014. Measuring the importance and practices of Lean values. The TQM Journal, 26(5), pp.463-474.

Ingelsson, P., 2013. Creating a Quality Management Culture Focusing on Values and Leadership. Doctoral Thesis. Östersund: Department of Engineering and Sustainable Development. Mid Sweden University.

Ingelsson, P., Bäckström, I. and Wiklund, H., 2010. Measuring the soft side of TQM and Lean. Paper presented at the 13th QMOD (Quality Management \& Organizational Development), Cottbus, Germany.

Janssen, N., Kant, I.J., Swaen, G.M.H., Janssen, P.P.M. and Schröer, C.A.P., 2003. Fatigue as a predictor of sickness absence: results from the Maastricht cohort study on fatigue at work. Occupational and Environmental Medicine, 60(1), pp.71-76.

Kongsbak, H., 2010. From Crisis to Global Competitiveness: Learning from a Spectacular Journey. AI Practitioner, 12(3), pp.10-14.

Lagrosen, Y., Bäckström, I. and Wiklund, H., 2012. Approach for measuring health-related quality management. The TQM Journal, 24(1), pp.59-71.

Liker, J. and Franz, J.K., 2011. The toyota way to continuous improvement: Linking strategy and operational excellence to achieve superior performance aut. United States of America: The McGraw-Hill Companies Inc.

Liker, J.K., 2004. The Toyota Way: 14 management principles from the world's greatest manufacturer. New York: McGraw-Hill.

Liu, N-C. and Liu, W-C., 2014. The effects of quality management practices on employees' well-being. Total Quality Management \& Business Excellence, 25(11-12), pp.1247-1261.

Nyberg, A., Bernin, P., Theorell, T., SALTSA \& Arbetslivsinstitutet, 2005. The impact of leadership on the health of subordinates. Stockholm: National Institute for Working Life Arbetslivsinstitutet. 
Radnor, Z.J. and Barnes, D., 2007. Historical analysis of performance measurement and management in operations management. International Journal of Productivity and Performance Management, 56(5/6), pp.384-396.

Seddon, J., 2005. Freedom from command \& control: Rethinking management for lean service. New York: Productivity Press.

Spear, S.J., 2004. Learning to lead at Toyota. Harvard Business Review, 82(5), pp.78-91.

Theorell, T. and Vogel, J., 2003. Health. Social Indicators Research. An international and Interdisciplinary Journal for Quality-of-life Measurement, 64(3), pp.471-493.

Watkins, J. M. and Cooperrider, D., 2000. Appreciative inquiry: a transformative paradigm. OD Practitioner, 32(1), pp.6-12.

Westlund, A. and Löthgren, M., 2001. The interaction between quality, productivity and economic performance: the case of Swedish pharmacies. Total Quality Management, 12(3), pp.385-296.

Whitney, D. and Trosten-Bloom, A., 2010. The Power of Appreciative Inquiry, A practical Guide to Positive Change., 2dn. San Francisco: Berrett-Koehler.

Whitney, D., Trosten-Bloom, A. and Rader, K., 2010. Appreciative Leadership, Focus on What Works to Drive Winning Performance and Build a Thriving Organization. New York: The McGraw-Hill.

Wolf, K., 2008. Health and productivity management in Europe. International Journal of Workplace Health Management, 1(2), pp.136-144.

Womack, J.P. and Jones, D.T., 2003. Lean thinking: banish waste and create wealth in your corporation. London: Free Press Business.

Zwetsloot, G. and Pot, F., 2004. The business value of health management. Journal of Business Ethics, 55(2), pp.115-124.

\section{ABOUT THE AUTHORS}

Ingela Bäckström, Associate Professor, Department of Quality Technology and Management, Mid Sweden University, Östersund, Sweden, e-mail: ingela.backstrom@miun.se

Pernilla Ingelsson, $\mathrm{PhD}$, Department of Quality Technology and Management, Mid Sweden University, Östersund, Sweden, e-mail: pernilla.ingelsson@ miun.se 